\title{
A PRODUÇÃO DAS ELITES ESCOLARES: escolas, famílias e cultura ${ }^{1}$
}

\section{Zaia Brandão*}

... uma prática, um objeto ou um discurso nunca é distinto ou vulgar, nobre ou comum, nele mesmo ou por ele mesmo, como acredita o senso comum elitista, ${ }^{2}$ mas somente em sua relação com outros objetos, outras práticas ou outros discursos (Bourdieu, 1989, p. 255).

Este artigo sintetiza os resultados de um survey desenvolvido junto a nove escolas de prestígio na cidade do Rio de Janeiro - confessionais, bilíngües, públicas e "alternativas" - esta última caracterizada por representar projetos pedagógicos inovadores nos anos 60 que enfatizavam a liberdade e autonomia na formação dos estudantes. O material empírico que produzido oferece um panorama a respeito das práticas familiares e escolares que se retroalimentam na produção de trajetórias institucionais bem sucedidas, por parte da maioria dos jovens que ingressam e permanecem nessas escolas. Trata-se de um estudo sobre o processo de conversão e reconversão de capitais (cultural, econômico, social, simbólico, escolar...) bastante con-

* Professor-Doutor da Pontifícia Universidade Católica do Rio de Janeiro, Centro de Teologia e Ciências Humanas Departamento de Educação. Marquês de São Vicente, 225 - $10^{\circ}$ andar - Gávea. Cep: 22453-900 - Rio de Janeiro, RJ Brasil. Telefone: (21) 35271817. zaia@edu.puc-rio.br

${ }^{1}$ Embora a redação deste trabalho seja de minha responsabilidade, este texto está fundamentado no trabalho coletivo do Grupo de Pesquisas em Sociologia da Educação da Pontifícia Universidade Católica do Rio de Janeiro - SOCED: Cynthia Paes de Carvalho, Diana Mandelert, Fernanda Braga, Hustana Vargas, Maria Cristina da Silva Galvão e Verena Giglio.

${ }^{2}$ Traduzimos "sens commum distingué" por "senso comum elitista". sistente com a hipótese de uma "circularidade virtuosa”, ou seja, de uma otimização dos processos de construção da qualidade de ensino, nas instituições investigadas.

\section{SOBRE O SURVEY}

Apesar de o estudo das elites escolares já estar legitimado na agenda da Sociologia da Educação, ainda assim, no campo da educação, o tema encontra resistências. Num país onde o sistema escolar é fortemente excludente - ou seja, cada vez mais, após incluir, exclui, ${ }^{3}$ o que acaba por legitimar e justificar a desigualdade -, estudar as elites escolares provoca uma certa censura, na maioria das vezes, de forma velada. A equipe da pesquisa, ao definir como seu objeto de pesquisa as "elites escolares", o fez na perspectiva relacional e a partir das representações sociais - reafirmadas e consagradas pela mídia-sobre as melhores escolas.

\footnotetext{
${ }^{3}$ Dados do censo escolar indicam a quase universalização do ensino fundamental. Consultar os dados disponíveis no INEP/MEC.
} 
A investigação baseou-se em nove escolas do Rio de Janeiro, recorrentemente apontadas não só pela mídia como também nos meios educacionais, como entre as melhores da cidade. Numa primeira etapa, após um trabalho exploratório com base em observações e entrevistas em uma das escolas, desenvolvemos um survey composto de três questionários (alunos, pais e professores) que nos permitiu produzir um material empírico suficiente para refletir sobre os processos de produção de qualidade de ensino ${ }^{4}$ nos diferentes tipos de instituições pesquisadas: duas confessionais, duas públicas, duas bilíngües, duas alternativas ${ }^{5} \mathrm{e} u m a$ escola judaica. ${ }^{6}$

Na fase atual da pesquisa,- após encaminhar o material produzido a partir do survey às escolas investigadas ${ }^{7}$ - a equipe da pesquisa está retornando às escolas para o aprofundamento do trabalho de campo com o recurso a observações, entrevistas e consultas a material institucional.

O banco de dados das nove escolas foi construído com base no material produzido a partir das respostas da totalidade dos alunos das $8^{\text {as }}$ séries das nove escolas (850 alunos). $O$ baixo retorno dos questionários dos pais (251) e professores (144) recomenda a relativização dessas respostas no momento da análise. No entanto, como os questionários foram construídos procurando cercar alguns construtos - clima escolar, apoio aos estudos, perfis sociodemográficos, relações entre

${ }^{4}$ Sobre as fases anteriores da pesquisa, é possível consultar um conjunto de textos divulgados no Boletim SOCED números 1 e 2, também disponível online no site do SOCED: www.soced.pro.br.

${ }^{5}$ Essa adjetivação,embora usual, encontrou algumas resistência por parte de uns poucos profissionais. Como não encontramos nenhum termo que expressasse melhor o sentido originário desse tipo de instituições surgidas nas décadas de 60/ 70 passadas, optamos por manter o termo que nos guiou na escolha de instituições que representam aqueles projetos pedagógicos que enfatizavam a liberdade e a autonomia das crianças e foram influenciadas por propostas educacionais como Summerhill, criada pelo educador inglês A. S. Neill.

${ }^{6}$ Esta escola não entrou no grupo das confessionais por se autodefinir como laica, voltada para a cultura judaica.

7 Tabelas com os dados de cada escola comparados com os dados globais das outras 8 escolas, e dois artigos com análises preliminares dos dados. Em duas dessas escolas, desenvolvemos um debate dos resultados com membros da equipe pedagógica. Embora a equipe da pesquisa tenha se proposto a ir a todas as escolas, problemas das agendas nas outras instituições não permitiram que esses debates acontecessem como previmos. os agentes educativos etc. - com questões correlatas para os três grupos (alunos, pais e professores), as análises desenvolvidas têm procurado, sempre que possível, articular as respostas dos diferentes agentes a partir dos questionários dos alunos.

Diana Mandelert, um dos membros da equipe da pesquisa, em sua dissertação de mestrado (Mandelert, 2005), procurou avaliar possíveis diferenças, a partir dos dados dos alunos, entre os perfis dos pais que responderam aos questionários e dos pais que não responderam. Segundo a autora, a comparação de algumas freqüências estaria sugerindo que os alunos cujos pais não responderam os questionários "teriam características de uma relação mais instrumental com a escola, marcada pela valorização do resultado escolar e não pela qualidade dos processos de ensino-aprendizagem” (Mandelert, p. 42). Essa hipótese será aprofundada na continuidade dessa pesquisa.

No caso dos dados relativos aos professores, pedimos aos colégios uma lista completa de docentes com dados sobre idade, instituição de origem, tempo de formado, ano de ingresso na escola, entre outros, com o objetivo de preencher algumas das lacunas do nosso material. Com o nosso retorno ao campo, além das entrevistas previstas com os agentes educacionais (professores e pais, principalmente), temos procurado complementar as informações disponíveis.

\section{REVENDO HIPÓTESES INICIAIS}

Ao início desta investigação, uma de nossas hipóteses centrais era de que o efeito agregado por essas escolas, em termos de qualidade de ensino, seria bem menor do que o suposto socialmente. A produção teórico-empírica sobre os processos de escolarização, desde a década de 60 do século passado, já vinha destacando amplamente a origem social dos estudantes como um dos principais determinantes do desempenho escolar. Portanto, provavelmente, as escolas apontadas como as melhores do Rio de Janeiro também teriam, nas características exógenas ao mundo escolar (os atri- 
butos socioeconômicos e culturais dos jovens e das famílias que conseguiam atrair para as suas instituições), os fundamentos da qualidade do seu ensino. A análise preliminar do material produzido, entretanto, levou-nos a rever essa hipótese. Uma série de indícios relevantes permitiu-nos refletir sobre as características institucionais (tipos de gestão, relações interpares, clima escolar, entre outras) que, em interação com fatores exógenos às escolas, estariam subjacentes à qualidade de ensino atribuída a essas escolas. Em que pese a validade da suposição de que a origem social dos estudantes é uma das variáveis mais importantes no processo de escolarização, a estrutura organizacional, que pudemos delinear da análise de nossos dados, ${ }^{8}$ parece contribuir para a produção de qualidade de ensino divulgada tanto pela mídia como por especialistas do campo educacional. Alguns desses aspectos são: a formação, as condições de trabalho e a experiência dos quadros docentes dessas escolas, as características de gestão institucional com a articulação em várias instâncias de coordenação do trabalho pedagógico, as motivações dos agentes pedagógicos e os contextos sociais do entorno pedagógico. Esse material da pesquisa poderá servir para compor uma agenda de debates sobre políticas educacionais voltadas para a melhoria da qualidade de ensino. Neste texto, destacaremos alguns desses aspectos. Cabe assinalar, no entanto, que representam apenas um primeiro ensaio nessa direção, e poderão sofrer modificações e revisões na continuidade da investigação.

\section{O público escolar}

... não é jamais possível, em todo caso, dizer com segurança quem, entre o agente e a instituição, escolhe realmente; se é o bom aluno que escolhe a escola ou se é a escola que o escolhe [...] (Bourdieu, 1989, p.198) (Tradução da autora).

A citação acima exprime adequadamente um dos fundamentos de nossas hipóteses prelimina-

${ }^{8}$ Com o retorno ao campo (fase atual da pesquisa), a consulta aos organogramas das escolas, as entrevistas com diretores e coordenadores e as observações in loco têm nos oferecido novas referências empíricas para o aprofundamento das análises sobre o funcionamento dessas escolas. res sobre as bases exógenas da produção da imagem de qualidade de ensino em escolas consideradas de excelência. O material de nosso survey, as entrevistas formais e informais com os dirigentes das instituições, a análise das propostas pedagógicas presentes nos sites das escolas e as características mais difusas do ambiente escolar que temos podido observar evidenciam, no seu conjunto, uma via de mão dupla no processo de escolha da escola e dos alunos.

Além das razões indicadas pelos pais nas respostas ao questionário, os valores, as normas, os estilos pedagógicos das escolas e todo um conjunto de pequenas coisas que compõem a ambiência onde se dão os primeiros contatos entre as famílias e as escolas (clima institucional) definem as condições das interações que acolhem ou distanciam a escola e a família. Parece, portanto, adequada a hipótese de que também a escola escolhe o seu público pela forma como se apresenta a ele. Estudando "a elite dos colégios paulistanos", Almeida (2004) indica o "forte controle" que essas escolas exercem na seleção de sua clientela, seja através de exames de seleção, ${ }^{9}$ seja através da própria seleção financeira decorrente do valor das mensalidades. Através desses expedientes, conseguem, segundo a autora, obter "a homogeneidade do alunado em termos da maneira de viver a escolarização" (Almeida, p. 34).

A coerência e consistência entre as práticas educativas familiares e escolares estão entre as condições de produção do bom desempenho, que fazem dessas instituições o locus de produção das

\footnotetext{
${ }^{9}$ Mesmo no caso das escolas públicas, o processo de seleção em mão dupla tende a funcionar. Os processos de seleção por sorteio, divulgados por editais, já exige a presença de certo volume de capital informacional e social por parte das famílias que procuram essas escolas, que as situa num plano superior das hierarquias sociais, mesmo quando provêem de setores populares. O contato com as equipes pedagógico-administrativas evidenciou uma efetiva preocupação com as alternativas a adotar, para manter os padrões de qualidade de ensino, desde que foram eliminados os exames de seleção e (ou) cursos de nivelamento para os sorteados, após os quais selecionavam-se os alunos que obtinham os melhores resultados. Afora estas características, as exigências de desempenho dessas instituições acabam funcionando como um filtro interno, seja através da reprovação, jubilação ou mesmo auto-eliminação (desistência) (Galvão, 2003).
} 
elites escolares. ${ }^{10}$ A seleção dos alunos (e suas famílias) pode, aparentemente, contrariar as leis do "mercado escolar". No entanto, a manutenção dos padrões de desempenho que definem a posição dessas escolas no ápice das hierarquias escolares é, por si só, a garantia de atrair um público cada vez mais afinado com os objetivos de distinção no sistema educacional. Cabe destacar, assim, que, para além das características da clientela, pudemos encontrar um conjunto de fatores intra-escolares que indicam perfis institucionais que agregam uma série de características que parecem otimizar as condições do trabalho docente e discente.

\section{O mundo natal e o desempenho escolar}

Mais da metade dos alunos (56\%) está na instituição investigada desde o início de sua escolarização, e 86\% nunca experimentou a repetência. Embora seja necessária uma análise mais rigorosa da questão, é possível levantar a hipótese de que a "fidelidade institucional" seja mais forte do que o percentual indicado, pois temos indícios de que algumas das mudanças de escola teriam ocorrido especialmente na passagem da educação "pré-escolar" para o ensino fundamental, como pudemos apurar através de conversas informais com dirigentes e alunos.

O baixo índice de repetência não surpreende nesse tipo de instituições: além de algumas delas não permitirem a matrícula de repetentes, a literatura tem apontado recorrentemente a generalização das estratégias preventivas do fracasso escolar entre os estratos médios e superiores da população que, normalmente, compõem a maior parte da população dessas escolas.

Entre essas estratégias preventivas, o recur-

${ }^{10} \mathrm{O}$ trabalho de campo tem confirmado essa suposição. Participamos, por exemplo, de uma reunião de pais de alunos de $8^{\mathrm{a}}$ série em uma dessas escolas, onde a equipe pedagógica, em inúmeros momentos, chamou a atenção dos pais para a necessidade de colaboração com as condições de um bom desenvolvimento da escolaridade dos filhos - seja na definição de um limite de tempo para os jovens navegarem na internet, seja na definiçã̃o da hora de dormir, seja no respeito às horas de chegada e saída da escola, assim como o uniforme. so ao professor particular é uma prática bastante usual. Recorreram a professores particulares $41 \%$ dos alunos; entretanto, 88\% destes declararam que o fizeram porque acharam necessário, ${ }^{11}$ indicando uma relativa autonomia desses jovens na definição das condições da própria escolaridade. Embora pudessem marcar mais de uma opção nessa questão, entre elas, meus pais acharam necessário e sugestão da escola/professor, os percentuais dessas últimas alternativas reforçam a presença de uma relação entre família e escola marcada pelo desenvolvimento da autonomia dos estudantes na definição de suas necessidades escolares. Indicaram que os pais acharam necessário $56 \%$ dos alunos, o que significa que $32 \%$ deles foram inteiramente autônomos em sua avaliação da necessidade de apoio extra-escolar. ${ }^{12}$ Em uma questão sobre deveres de casa, apenas 11\% dos alunos afirmaram que fazem o dever de casa porque pais obrigam, ${ }^{13} \mathrm{o}$ que reforça a hipótese da autonomia da maioria desses jovens. Cabe destacar, ainda, o baixo percentual (13\%) dos alunos que indicaram que houve sugestão da escola/professor para recorrer a professores particulares. Esse dado é expressivo da imagem de qualidade de ensino que essas escolas precisam cultivar para atrair certo perfil de alunos e famílias e manter intacto o seu status de "boas escolas", que cumprem integralmente sua função de preparar as elites escolares do Rio de Janeiro.

... em tudo o que define a relação de um grupo de estudantes com os seus estudos, aparece a rela-

${ }^{11}$ O quesito era Por que você precisou de professor particular? Com as opcões: achei necessário - meus pais acharam necessário - sugestão da escola/professor. Os alunos podiam marcar mais de uma opção.

${ }^{12}$ A questão da estruturação das relações familiares com a escolaridade dos filhos tem sido objeto de pesquisa da sociologia da educação. Lahire (1997) já assinalou o caráter mais heterônomo das famílias de camadas populares que se utilizam, bem mais do que os quadros médios, de punições e imposições de regras, sem discussão, no trato da educação dos filhos, minimizando as condições de desenvolvimento da autonomia, característica importante para o bom desempenho escolar. Dubar (1995), na mesma direção, assinala o caráter mais flexível da estruturação do meio familiar, que cria condições favoráveis ao desenvolvimento da iniciativa e responsabilidade entre os filhos (ibid p. 21)

${ }^{3}$ A questão era: Em relação aos deveres de casa você: Faz sem atraso? Faz ainda na escola? Faz porque valem nota? Faz porque os pais obrigam? Faz assistindo televisão? 
ção fundamental que sua classe social mantém com a sociedade global, com o sucesso social e com a cultura (Bourdieu e Passeron, 1985, p. 36) (Tradução da autora).

Nossos dados oferecem elementos que permitem um olhar mais detalhado sobre o perfil das famílias e alunos que essas escolas atraem. Certas características do cotidiano desses estudantes indicam condições sociais de uma estruturação da vida familiar ${ }^{14}$ em que o contato mais freqüente entre pais e filhos favorece a transmissão da herança. São estilos de vida que facilitam um convívio, no qual relações mais horizontais (conversas) estimulam que os "herdeiros herdem a herança": $49 \%$ dos jovens afirmaram sempre almoçar ou jantar com os pais e $35 \%$ quase sempre o fazem. A importância desse contato para a reprodução dos habitus familiares é reafirmada pela freqüência com que conversam com eles "sobre a continuidade dos estudos" (90\%), "sobre a futura profissão" (71\%), "sobre filmes" (80\%), "sobre TV" (69\%) e "sobre outros assuntos” (93\%). Esse último percentual, de caráter residual, merece especial atenção, pois estaria indicando o amplo elenco de temáticas que permeiam as conversas entre pais e filhos no grupo pesquisado. ${ }^{15}$ Identificando as lentes sobre aquelas temáticas que mais se aproximam dos conteúdos valorizados pelos currículos escolares, ${ }^{16}$ encontramos $47 \%$ dos alunos que afirmaram conversar, quase sempre ou sempre, "sobre livros" com os pais, e $33 \%$ que indicaram o mesmo, sobre "museus e exposições".

14 Essas condições não são democraticamente distribuídas; as famílias de camadas populares são submetidas a condições de vida, trabalho, transporte, moradia etc. que dificultam as trocas familiares mais freqüentes. Entretanto, mesmo quando elas existem, a distância dos habitus culturais familiares dos padrões valorizados pela escola não permitiriam que essas trocas se convertessem em capital escolar.

${ }^{15}$ Foram apresentadas sete opções de conversas: sobre filmes ,sobre livros, sobre programas de TV, sobre museus e exposições, sobre a continuidade de seus estudos, sobre a futura profissão e sobre outros assuntos.

${ }^{16}$ É importante lembrar que a maioria dessas escolas não permite a permanência ou reincidência de repetências. Mesmo nas escolas públicas, o "jubilamento" é uma prática que penaliza, sobretudo, os alunos dos estratos populares que têm acesso às escolas públicas de prestígio em nosso sistema escolas. A esse respeito, consultar Galvão (2003).

\section{A conversão e reconversão de capitais}

O patrimônio econômico e o patrimônio cultural, conjunto de recursos do grupo familiar em estado objetivado, sob a forma de bens materiais (por exemplo, os livros, os instrumentos musicais ou, atualmente, os computadores) ou, no caso da cultura, em estado incorporado em cada membro do grupo familiar, tendem a impor aos seus detentores o reconhecimento prático e tácito do seu valor, à medida que favorecem o desenvolvimento de disposições ajustadas à posição social que lhes caracteriza (Bourdieu, 1989, p. 226) (Tradução da autora).

O material empírico que produzimos oferece um panorama a respeito das práticas familiares e escolares que se retroalimentam na produção de trajetórias institucionais exitosas, por parte da maioria dos jovens que ingressam e permanecem nessas escolas. Trata-se de um processo de conversão e reconversão de capitais (cultural, econômico, social, simbólico, escolar...), consistente com a hipótese de uma "circularidade virtuosa", ou seja, de uma otimização dos processos de construção da qualidade de ensino, nas instituições investigadas. ${ }^{17}$

A valorização da leitura e da cultura letrada no meio familiar é reiterada pelas respostas dos alunos às questões relativas às práticas de leitura: ${ }^{18} 60 \%$ indicaram que discordam ou discordam totalmente da afirmação só lê o necessário; 29\% discordam e $62 \%$ discordam totalmente da alternativa ler é perda de tempo. Ou seja, apenas 9\% concordam com aquela afirmação. Além disso, desses jovens, 38\% concordam ou concordam totalmente com a alternativa ler é uma das minhas diversões preferidas, e 22\% afirmaram adoro ir a livrarias. Quanto aos tipos de leitura mais freqüentes, ${ }^{19} 67 \%$ indicam páginas de internet, $56 \%$ ficção e $45 \%$ revistas informativas. Essas preferências estariam indicando o entrecruzamento das influências dos pares (jovens), da escola e da famí-

${ }^{17}$ Consultar a respeito, Brandão, Mandelert, de Paula (2005).

${ }_{18}$ As alternativas do questionário eram concordo totalmente, concordo, discordo, discordo totalmente.

19 As alternativas eram quase sempre, algumas vezes e nunca à questão "Com que freqüência você lê:", seguida dos diversos tipos de leituras. Os percentuais apresentados representam as respostas em "quase sempre". 
lia, e do capital cultural materializado no ambiente familiar (bibliotecas e assinatura de revistas semanais). ${ }^{20}$ Além dessas características do público escolar, com o nosso retorno ao campo, tem sido possível observar sinais claros da valorização das práticas de leitura e escrita nessas escolas: desde murais com comentários dos alunos sobre leituras, informações nas páginas da internet sobre novas aquisições da biblioteca, eventos culturais e feira de livros e cultura promovidos na e pelas instituições, até a observação das aulas, onde o incentivo à leitura está quase sempre presente, seja explícita ou implicitamente.

As condições de ampliação do volume e da estrutura do capital cultural podem ser inferidas, ainda, pelos percentuais de assistência a programas de TV. Os programas prediletos desses jovens são seriados (94\%), humorísticos (87\%) e shows de música (81\%), acompanhados de assistência a jornais e noticiários (79\%), entrevistas (69\%) e documentários (62\%).

Essas condições encontram-se, assim, combinadas às pautas de gosto juvenil, com a valorização do capital informacional, própria dos estratos da população com níveis de escolarização superior, como é o caso da maioria dos pais dos alunos que freqüentam as escolas investigadas. ${ }^{21}$ Os quesitos dos questionários referentes às práticas sociais dos alunos, por sua vez, reiteram a probabilidade de esses jovens virem a se enquadrar, até a vida adulta, na situação de "herdeiros herdados pela herança”, conforme a expressão cunhada por Bourdieu (1993), para significar a conversão do capital social familiar em outros tipos de capital. As práticas que obtiveram os percentuais mais elevados (quatro ou mais vezes por ano) foram: freqüências a cinema

${ }^{20} \mathrm{O}$ percentual de apenas $17 \%$ indicando a leitura quase sempre de jornais é bastante consistente com a idade destes jovens (13/14 anos), fase em que o hábito de leitura cotidiana de jornais raramente ocorre.

${ }^{21}$ Os níveis de escolaridade dos pais são: $47 \%$ superior e $39 \%$ pós-graduação (especialização, mestrado, doutorado). No caso das mães: $51 \%$ superior, $37 \%$ pós-graduação. Apenas $13 \%$ dos pais e $11 \%$ das mães indicaram ter cursado apenas o nível médio. É importante lembrar que fazem parte dessa amostra pais das escolas públicas, o que inclui pais de setores de camadas populares, portanto, com menores condições contextuais de desenvolvimento de trajetórias escolares longas.
(86\%) e a livrarias (48\%), ambas indicando a conversão de capital econômico em cultural. ${ }^{22}$

\section{O CLIMA ESCOLAR}

A revisão da hipótese de que as escolas de maior prestígio, normalmente, agregam menor valor escolar do que o suposto socialmente impôs-se na medida em que avançávamos na investigação. Duas foram as observações que nos levaram a isso: algumas indicações nas respostas ao survey de que o clima escolar das escolas investigadas teria um impacto positivo tanto sobre os alunos como sobre as condições de trabalho dos professores; e as características das práticas docentes e da gestão do trabalho pedagógico, inferidas das observações de campo cruzadas com entrevistas e os dados produzidos a partir do survey. Em conjunto, essas observações sugerem a presença de estilos de gestão escolar que favorecem o fluxo de informações cruzadas $^{23}$ - proporcionando momentos de interação e debates entre os agentes educativos que articulam, monitoram, avaliam e reorientam as ações pedagógicas.

A percepção dos alunos acerca do ambiente escolar, dos professores e do processo de ensinoaprendizagem indica um clima favorável à aprendizagem. ${ }^{24}$ Dos alunos investigados $90 \%$ (percentual obtido pela soma das alternativas concordo, concordo totalmente) vêem essas escolas como luga-

${ }^{22} \mathrm{O}$ elenco de práticas do questionário era: livraria, cinema, teatro, ópera ou concerto, biblioteca da escola; as opções eram: nunca, 1 a 2 vezes por ano, 3 a 4 vezes por ano, 4 ou mais vezes por ano.

${ }^{23}$ Garcia, Hypolito e Vieira (2005), em artigo sobre as identidades docentes, desenvolvem uma taxionomia "modelos de profissionalismos", em que incorporam uma crítica ao "profissionalismo como trabalho extensivo" (modelo mais próximo ao que estamos descrevendo). Segundo essa crítica, haveria, nesses casos, um controle ideológico alocado "nas mãos firmes dos administradores, dos políticos e do capital transacional.”Daí decorreria "uma autoridade despersonalizada - uma docência de resultados confundida com profissionalismo" (p. 51-52). Esse tipo de crítica deriva da perspectiva hoje bastante corrente no campo da educação que questiona radicalmente qualquer proposta de avaliação do trabalho docente.

${ }^{24}$ Ver, a respeito, Bressoux (2003). O autor ao analisar os resultados das pesquisas sobre os efeitos agregados pelas escolas onde as estratégias adequadas de apoio e incentivo aos jovens da parte do professor são destacadas. 
res onde fazem amigos facilmente; para 61\%, a maioria dos professores continuam a explicar a matéria até que todos os alunos entendam; e, para $80 \%$, os professores, freqüentemente, incentivam os alunos a melhorar, assim como $87 \%$ acham que eles freqüentemente estão disponíveis para esclarecer as dúvidas dos alunos.

As características do corpo docente, por sua vez, evidenciam a presença, nas escolas investigadas, de um grupo de professores com larga experiência: $68 \%$ tem mais de 40 anos; $37 \%$ formou-se há mais de 25 anos e 38\% entre 16 a 25 anos. Trabalham na escola investigada, há mais de 16 anos, 30\% dos professores que responderam os questionários, e 40\% estão de 6 a 15 anos na instituição.

Segundo Cousin (1998), a estabilidade do corpo docente e da equipe administrativa é uma das pré-condições fundamentais para a construção de "políticas institucionais de sucesso". O tempo de magistério, nessas escolas, pode ser inferido como um indicador das boas condições de trabalho oferecidas por essas instituições. Cousin enumera, entre outros indicadores importantes para a construção da excelência escolar, a imagem perante a clientela, a coesão institucional e a adesão do corpo docente ao projeto institucional. Os dados acerca da percepção da maioria dos alunos, comparados aos descritos no questionário dos pais e professores, indicam a existência de um clima institucional e pedagógico positivo nessas escolas, o que as confirma como instituições que implementam projetos pedagógicos bem sucedidos. ${ }^{25}$

Quanto ao salário, 56\% dos professores afirmam auferir um salário bruto acima de R \$ 3.600,00 (36\% entre $\mathrm{R} \$ 3.601,00$ e $\mathrm{R} \$ 4.400,00$ e 20\% mais de $\mathrm{R} \$ 4.400,00$ ), considerado por $60 \%$ deles como remuneração acima da média para a categoria profissional. Entretanto, cabe destacar que um terço desses professores, trabalham em três ou mais escolas. Esse dado nos parece surpreendente e indi-

${ }^{25}$ Para $88 \%$ dos professores que responderam aos questionários a maioria dos colegas está comprometida com que todos alunos aprendam; para 66\%, a maioria assume a responsabilidade de melhorar a escola e, para 69\%, a maioria sente-se responsável pelos resultados alunos. ca a gravidade da situação do magistério em nosso país. As características de formação, experiência e desempenho desses professores os coloca seguramente entre os melhores da categoria, dos quais uma boa parte em final de carreira. Ora, os dados salariais, ainda que representem padrões mais elevados do que a média auferida pela categoria, não parecem compatíveis com os níveis salariais alcançados por outros profissionais de nível superior, em instituições ou empresas de prestígio, ao final da carreira.

\section{HIPÓTESES A EXPLORAR}

É preciso destacar que a categorização dos pares institucionais com que trabalhamos confessionais, bilíngües, alternativas, públicas deve ser lida muito mais como uma definição operacional do que como tipos ideais weberianos. A volta ao campo torna cada vez mais clara as singularidades institucionais. Dentro de um mesmo par, essas singularidades (dos projetos, do uso e estética do espaço escolar, dos perfis das famílias, da articulação do trabalho pedagógico, etc.) têm nos parecido mais relevantes para a exploração do problema sob investigação, do que as semelhanças pressupostas pela classificação inicial do desenho da pesquisa.

A aproximação do cotidiano escolar, que o retorno ao campo vem favorecendo, nos ajudará a refinar nossas interpretações sobre as singularidades institucionais, e as similaridades ou não do clima escolar e das características de gestão pedagógico-administrativa. Até o momento, nosso trabalho vem confirmando a presença, nessas escolas, de equipes docentes razoavelmente bem entrosadas, provavelmente, em decorrência de uma estrutura pedagógico-administrativa que favorece as trocas entre pares e um maior comprometimento coletivo com o projeto (político pedagógico) da instituição.

Entre as hipóteses sobre as condições que seriam necessárias, ainda que não suficientes, à construção de um ambiente escolar propício a um 
trabalho pedagógico de qualidade, caberia destacar, até o momento: profissionais bem qualificados, que encontram condições de trabalho e remuneração acima da média em relação à da sua categoria profissional, e um estilo de gestão institucional que parece ter um efeito de "contaminação positiva" ${ }^{26}$ sobre o clima escolar de responsabilidade coletiva sobre os resultados da aprendizagem. ${ }^{27}$ As observações institucionais, como já assinalamos, vêm reiterando a existência de várias instâncias de coordenação (de turmas, de disciplinas, de segmento etc.) que parece estimular o desenvolvimento de equipes e intensificar as condições de comprometimento coletivo com as ações institucionais. O que apresentamos, entretanto, são apenas alguns indícios das condições de trabalho e gestão institucional que parecem criar condições para que essas escolas desenvolvam um tipo de trabalho pedagógico que permite situá-las entre as melhores escolas do Rio de Janeiro.

(Recebido para publicação em novembro de 2006) (Aceito em abril de 2007)

\section{REFERÊNCIAS}

ALMEIDA, Ana Maria F. de; NOGUEIRA, Maria Alice (Orgs.) A escolarização das elites. Um panorama internacional da pesquisa. Petrópolis: Vozes, 2002.

BOURDIEU, Pierre. Les Héritiers. Les étudiants et la culture. Paris: Éditions de Minuit. 1985.

. La noblesse d' État. Grandes écoles et esprit de corps. Paris: Éditions de Minuit. 1989.

. Razões práticas: sobre a teoria da ação. Campinas: Papirus, 1996

2003.

Escritos de educação. 5. ed. Petrópolis: Vozes,

BRANDÃO, Zaia; LELIS, Isabel. Elites acadêmicas escolarização dos filhos. Educação \& Sociedade, São Paulo, Cortez, n. 83, ago., 2003.

${ }^{26}$ Essa é uma questão que está sendo objeto de atenção especial na atual fase de retomada do trabalho de campo. Tudo indica que o bom desempenho dos professores (inferido tanto pelas respostas dos questionários dos alunos sobre os professores, como dos questionários dos professores sobre o trabalho dos colegas) é o resultado do que estamos qualificando de uma "contaminação positiva” interpares.

${ }^{27}$ Apesar do 1/3 dos professores trabalharem em 3 e mais escolas, como observado anteriormente, cabe destacar que $40 \%$ dos docentes das escolas investigadas trabalham apenas em uma escola.
; MANDELERT, Diana; DE PAULA, Lucília. A circularidade virtuosa. Cadernos de Pesquisa, [S.1.], v. 35, n. 126, set./dez., 2005

BRESSOUX, Pascal. As pesquisas sobre o efeito-escola e o efeito-professor. Trad. Isabel Cristina Rabelo Gomes. Educação em Revista: UFMG. Belo Horizonte, n. 38, dez., 2003.

COUSIN, Olivier. L'Efficacité des collèges - sociologie de l'effet établissement. Paris: Presses Universitaires de France, 1998.

DANTAS, Manoel. A lógica do capital-informação: a fragmentação dos monopólios e a monopolização dos fragmentos num mundo de comunicações globais. Rio de Janeiro: Contraponto. 2002.

FRANCO, Creso. Educação das elites no Brasil: a Bélgica não existe. Trabalho e Sociedade, Rio de Janeiro, v. 2, n. 4, 2002.

GARCIA; HYPOLITO; VIEIRA. As identidades docentes como fabricação da docência. Educação e Pesquisa , [S.l.], v. 31, n. 1, 2005

GALVÃO, Maria Cristina da Silva. A jubiliação no Colégio Pedro II, que exclusão é essa? 2003. Dissertação (Mestrado) - Faculdade de Educação da UFRJ.

LAHIRE, Bernard. Sucesso escolar nos meios populares: as razões do improvável. Trad. Ramon Américo Vasques e Sonia Goldfeder. São Paulo: Ática, 1997.

MANDELERT, Diana. Pais na gestão da escola: mudam as relações? Uma análise sociológica de uma instituição judaica. 2005. Dissertação (Mestrado) - PUC-Rio: Departamento de Educação.

NOGUEIRA, M. A. A construção da excelência escolar: um estudo de trajetórias feito com estudantes universitários provenientes das camadas médias intelectualizadas. In: _ ROMANELLI,G; ZAGO, N. (Orgs.) Família \& escola: trajetórias de escolarização em camadas médias e populares. Petrópolis: Vozes, 2000. 


\section{A PRODUÇÃO DAS ELITES ESCOLARES:} escolas, famílias e cultura

\section{Zaia Brandão}

Este artigo sintetiza os resultados de um survey desenvolvido result This paper synthesizes the junto a nove escolas de prestígio na prestige schools in the city of Rio de cidade do Rio de Janeiro. Dentre Janeiro. Among them, there are elas, encontram-se escolas confessional, bilingual, public confessionais, bilíngües, públicas e schools and also "alternative" "alternativas" - expressão utilizada expression used in the sixties for nos anos 60 para representar proje- innovative pedagogic projects that tos pedagógicos inovadores que emphasized the freedom and enfatizavam a liberdade e autono- autonomy in the students' formation mia na formação dos estudantes. O - schools. The empiric material we material empírico que produzimos produced offers a panorama oferece um panorama a respeito das regarding the family and school práticas familiares e escolares que practices that feed themselves in the se retroalimentam na produção de production of successful institutional trajetórias institucionais bem suce- paths, on the part of most of the didas, por parte da maioria dos jo- youths that enter and stay at those vens que ingressam e permanecem schools. This is a process of nessas escolas. Trata-se de um pro- conversion and reconversion of culcesso de conversão e reconversão de tural, economical, social, symbolic, capitais (cultural, econômico, soci- academic... capitals quite consistent al, simbólico, escolar...) bastante with the hypothesis of a "virtuous consistente com a hipótese de uma circle", that is, of an optimization of "circularidade virtuosa", ou seja, de the processes of construction of the uma otimização dos processos de teaching quality, in the investigated construção da qualidade de ensino, institutions.

nas instituições investigadas.

KEY WORD: institutional trajectories,

Palavras-Chave: trajetórias teaching quality, prestige schools, soinstitucionais, qualidade do ensino, cial capital. escolas de prestígio, capital social.
LA PRODUCTION DES ELITES SCOLAIRES: écoles, familles et culture

\section{Zaia Brandão}

Cet article présente la synthèse des résultats d'un survey, réalisé dans neuf écoles de prestige de la ville de Rio de Janeiro, y compris des écoles confessionnelles, bilingues, publiques et "alternatives" - expression employée dans les années 60 pour parler des projets pédagogiques innovateurs où liberté et autonomie pour la formation des étudiants étaient mises en évidence. Le matériel, produit à partir d'un procédé empirique, offre un panorama des pratiques familiales et scolaires qui se rétro alimentent dans la production detrajectoires institutionnelles réussies par une majorité de jeunes qui sont entrés et sont restés dans ces écoles. Il s'agit d'un processus de conversion et de reconversion de capitaux (culturel, économique, social, symbolique, scolaire...) cohérent avec l'hypothèse d'une "circularité vertueuse", c'est-à-dire d'une optimisation des processus de construction de la qualité de l'enseignement dans les institutions analysées.

MOTS-CLÉS: trajectoires institutionnelles, qualité de l'enseignement, écoles de prestige, capital social

Zaia Brandão - Doutora e Mestre em Educação pela Pontifícia Universidade Católica do Rio de Janeiro. Graduada em Pedagogia pela Pontifícia Universidade Católica do Rio de Janeiro (1961). Atualmente é professor associado da Pontifícia Universidade Católica do Rio de Janeiro. Tem experiência em Sociologia da Educação, atuando principalmente nos seguintes temas: sociologia da educação, capital cultural, pesquisa em educação, escolarização das elites e qualidade de ensino. 